\title{
A social work study on welfare receivers' quality of life
}

\author{
Mohammad Reza Iravani*
}

Department of Social Work, Islamic Azad University of Khomeinishahr, Khomeinishahr Branch, Daneshjou Blvd, Iran

\begin{tabular}{|c|c|}
\hline A R T I C L E I N F O & A B S T RACT \\
\hline $\begin{array}{l}\text { Article history: } \\
\text { Received June } 25,2011 \\
\text { Received in Revised form } \\
\text { August, } 28,2011 \\
\text { Accepted } 30 \text { August } 2011 \\
\text { Available online } \\
\text { 1 September } 2011 \\
\text { Keywords: } \\
\text { Quality of life } \\
\text { Welfare programs }\end{array}$ & $\begin{array}{l}\text { Social welfare plays an important role on helping needy people build their future. There is no } \\
\text { doubt that a good social welfare program in any country could indirectly reduce rates of crimes } \\
\text { and violence. In this study, we examine the quality of life between welfare receivers and } \\
\text { ordinary people. The proposed study of this paper designs a questionnaire consists of nine } \\
\text { questions and distribute between two groups of } 50 \text { people. The questions are based on Likert } \\
\text { scale from very low to very high and the feedbacks are analyzed using some statistical tests. } \\
\text { The results indicate that typical ordinary people have better life style in terms of nutrition, } \\
\text { healthcare, housing and shelter, education, employment, income, social relationships, marital } \\
\text { status, entertainment than welfare receivers do. }\end{array}$ \\
\hline
\end{tabular}

Social welfare

Life expectation

\section{Introduction}

During the past few years, there have been different attempts to design suitable social welfares to help people reach better life style. There is no doubt that when the gap between various groups of people in a society becomes bigger, there will be an increase trend on rates of crime, violence, etc. (Rose, 2001; Eamon \& Kopels, 2004; McKinnish, 2007).

Any attempt to increase the quality of life will create an opportunity to reduce social problems. However, there are always people who wish to abuse social welfare trying to work on black market and receive welfare money. There are people who apply for immigrating to some countries solely based on abusing their welfare programs. Nannestad (2007) surveyed the relationship between immigration and welfare program for a 15 years period. Fiva (2009) investigated whether welfare program could affect people's residency or not. Onderstal (2009) designed a model to help those welfare receivers who actively looking for job to get a better job opportunity. Aidukaite (2009) surveyed the impact of various traditional welfare programs on people's lives.

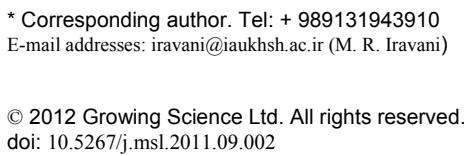


Diwan (2000) studied the relationship between the quality of life and wealth. Diwan's economic practices and policies focused on the maximization of material wealth only with minimal concern for its negative effects and provided suggestive economic policies and ideas regarding family, community and overconsumption. Massam (2002) reviewed the general concept of quality of life in public planning and private living. The search for meaningful definitions and ways to measure and describe the quality of life (QOL) was the objective of his paper. He argued that planners needed to pay close attention to the idea of QOL in order to assess the effects of plans and projects on places and lives of all citizens. In addition, the linkages between QOL and the concept of sustainability were explored. Massam also presented a review of a wide variety of literature on QOL and a review of the relationships between QOL and the public good. An overview and critique of the variety of indicators used to measure QOL was offered with example of specific projects. A number of case studies were reviewed and particular attention was placed on a set of six recent initiatives in Canada to define and measure QOL. A detailed case study on the perceived QOL of residents in three towns near to Puerto Vallarta, Mexico was presented as part of a larger project on the effects of tourism on the QOL of residents in small communities near to international tourist resorts. A description of the use of multicriteria techniques for analyzing data on QOL was presented as part of the Puerto Vallarta project.

The proposed study of this paper attempts to study the relationship between different things, which could impact the quality of life. The proposed study of this paper attempts to see how much welfare receivers have lost the quality of their lives. The following definition could help understand what we mean by each term used in this paper.

There is a meaningful relationship between the welfare receivers and regular people in the following items,

1. Nutrition

2. Health care and medication

3. Housing and shelter

4. Education and ethics

5. Employment

6. Income

7. Social relationships

8. Marital status

9. Leisure and entertainment

10. Quality of life

The first item is nutrition or nourishment, which is the provision to cells and organisms of the necessary food to support life. In fact, a healthy diet itself could prevent many common health problems such as osteoporosis, heart decease, etc. A person who receives less than 2000 calorie per day is suffering from malnutrition. In addition, anyone needs a minimum level of protein. A person who receives only $80 \%$ protein is considered damaged and anyone who receives between $80 \%$ and $90 \%$ protein is vulnerable. A healthy nutrition is normally defined based on some important criteria such as the ratio of amount of calorie/protein absorbed from food on the amount of needed calorie/protein to perform normal activities. Healthcare is another important parameter on quality of life. This item is defined based on different criteria such as the life expectancy, regular mortality, children mortality, pregnant mortality, etc. There are also other standard such as the ratio of the people's access to hospitals, physician, pharmacy, radiology, etc. Healthcare prevention facilities such as the access to clean water and washroom are other related criteria.

Housing or shelter is another important factor, which plays an important role on quality of life. A good housing and shelter could create more comfort and peace in mind, which leads to better life's quality. The quality of housing can be measured depending on the location, area, materials, etc. 
Education is another criterion, which plays an important role on people's lives and there are some evidences to believe that people with good educational background or job skills have better chance of finding job. There are different criteria associated with job in society such as the levels of average age of people with job, the average educational level of people with job, etc.

Income is another important factor on the quality of life and it can be considered as a basis of people's life style. A family of low income may not be able to spend sufficient fund on health care, education, etc., which means a lower standard of life. Social relationships, marital status and entertainment are other factors, which could significantly contribute to quality of life.

The proposed model of this paper selects two samples of fifty people from those who receive welfare and those who do not receive welfare. A questionnaire consists of various personal characteristics as well as some qualitative questions are distributed among them and theiry feedbacks are analyzed based on some descriptive and statistical tests. The organization of this paper is as follows. We first present details of our survey in section 2 and the statistical observations are analyzed in section 3. Finally, concluding remarks are given in the last to summarize the contribution of this paper.

\section{Proposed study}

The primary objective of this survey is to compare the quality of life between the people who receive welfare and those who do not. All questions of our survey are prepared based on Likert (Likert, 1932) scale in five descriptive terms from very low to very high. Table 1 summarizes some of the necessary information of people who participated in our survey.

Table 1

Personal characteristics of participants in terms of the quality of food and nutrition

\begin{tabular}{lccccc}
\hline \multirow{2}{*}{\begin{tabular}{l} 
Qutrition \\
\cline { 2 - 6 }
\end{tabular}} & \multicolumn{2}{c}{ Welfare receiver } & \multicolumn{2}{c}{ Regular people } & \\
\hline Very low & 5 & 10 & 1 & 2 & Total \\
Low & 13 & 26 & 7 & 14 & 6 \\
Medium & 21 & 42 & 17 & 34 & 38 \\
High & 6 & 12 & 17 & 34 & 23 \\
Very high & 5 & 10 & 8 & 16 & 13 \\
Sum & 50 & 100 & 50 & 100 & 100 \\
\hline
\end{tabular}

According to the results of Table 1 only 22 percents of welfare receivers enjoy good quality nutrition whereas 50 percents of ordinary people believe they receive good quality food. The other question we asked from the people who took part in our survey was the level of health care these groups encountered. Table 2 summarizes details of our survey on this question.

Table 2

Personal characteristics of participants in terms of the quality of health care

\begin{tabular}{lccccc}
\hline Healthcare & \multicolumn{2}{c}{ Welfare receiver } & \multicolumn{2}{c}{ Regular people } & \\
\cline { 2 - 6 } Quality & Frequency & Percentage & Frequency & Percentage & Total \\
\hline Very low & 12 & 24 & 2 & 4 & 14 \\
Low & 22 & 44 & 6 & 12 & 28 \\
Medium & 11 & 22 & 13 & 26 & 24 \\
High & 3 & 6 & 24 & 48 & 27 \\
Very high & 2 & 4 & 5 & 10 & 7 \\
Sum & 50 & 100 & 50 & 100 & 100 \\
\hline
\end{tabular}


Based on the results we received from the people who took part in our survey, only 10 percents of the welfare receivers were happy with their healthcare conditions while this rate was approximately 58 percents with the regular people who participated in our survey. Another question was on the quality of their lives in terms of having good housing and shelter and Table 3 presents a summary of our survey.

Table 3

Personal characteristics of participants in terms of the quality of housing and shelter

\begin{tabular}{lccccc}
\hline Housing & \multicolumn{2}{c}{ Welfare receiver } & \multicolumn{2}{c}{ Regular people } & \\
\cline { 2 - 6 } Quality & Frequency & Percentage & Frequency & Percentage & Total \\
\hline Very low & 5 & 10 & 0 & 0 & 5 \\
Low & 23 & 46 & 6 & 12 & 29 \\
Medium & 14 & 28 & 17 & 34 & 31 \\
High & 4 & 8 & 19 & 38 & 23 \\
Very high & 4 & 8 & 8 & 16 & 12 \\
Sum & 50 & 100 & 50 & 100 & 100 \\
\hline
\end{tabular}

According to our survey, only 16 percents of the people who participated in our survey enjoyed high quality housing whereas 54 percents of the ordinary people were happy on the place they lived in. Employment was another question of our survey and the results of the survey are given in Table 4.

\section{Table 4}

Personal characteristics of participants in terms of the quality of job

\begin{tabular}{lccccc}
\hline The quality of & \multicolumn{2}{c}{ Welfare receiver } & \multicolumn{2}{c}{ Regular people } & \\
\cline { 2 - 6 } participants' job & Frequency & Percentage & Frequency & Percentage & Total \\
\hline Very low & 5 & 10 & 1 & 2 & 6 \\
Low & 22 & 44 & 7 & 14 & 29 \\
Medium & 15 & 30 & 12 & 24 & 27 \\
High & 5 & 10 & 21 & 42 & 26 \\
Very high & 2 & 4 & 9 & 18 & 11 \\
Sum & 50 & 100 & 50 & 100 & 100 \\
\hline
\end{tabular}

It is clear from Table 4 that only 7 welfare receivers representing 14 percents are either highly or very highly satisfied from the job they had but the numbers for regular people was 30 or 60 percents which means regular people are mostly interested in their job. Income is the other question of our survey and based on our survey people expressed their interests and the results are summarized in Table 5.

\section{Table 5}

Personal characteristics of participants in terms of the income

\begin{tabular}{lccccc}
\hline \multirow{2}{*}{$\begin{array}{l}\text { inc quality of } \\
\text { income }\end{array}$} & \multicolumn{2}{c}{ Welfare receiver } & \multicolumn{2}{c}{ Regular people } & \\
\cline { 2 - 6 } & Frequency & Percentage & Frequency & Percentage & Total \\
\hline Very low & 27 & 54 & 1 & 2 & 28 \\
Low & 8 & 16 & 10 & 20 & 18 \\
Medium & 14 & 28 & 25 & 50 & 39 \\
High & 1 & 2 & 10 & 20 & 11 \\
Very high & 0 & 0 & 4 & 8 & 4 \\
Sum & 50 & 100 & 50 & 100 & 100 \\
\hline
\end{tabular}

According to our survey, no welfare receiver is very much satisfied with his/her income and only 2 people indicated that they are relatively satisfied with their job. This figure comes to 28 percent among ordinary people. In fact, over 70 percents of welfare receivers are completely unhappy with their income whereas this figure is about 48 percent with ordinary people. One important observation 
in our survey is to see how people think about their social relationships as explained earlier and Table 6 summarizes the results of our survey.

Table 6

Personal characteristics of participants in terms of the social relationship

\begin{tabular}{lccccc}
\hline The quality of & \multicolumn{2}{c}{ Welfare receiver } & \multicolumn{2}{c}{ Regular people } & \\
\cline { 2 - 6 } social relationship & Frequency & Percentage & Frequency & Percentage & Total \\
\hline Very low & 1 & 2 & 0 & 0 & 1 \\
Low & 10 & 20 & 5 & 10 & 15 \\
Medium & 19 & 38 & 8 & 16 & 27 \\
High & 9 & 18 & 28 & 56 & 37 \\
Very high & 11 & 22 & 9 & 18 & 20 \\
Sum & 50 & 100 & 50 & 100 & 100 \\
\hline
\end{tabular}

While 40 percents of the welfare receivers are happy with their social relationship, this number is about 74 percents among ordinary people. Marital status was another question of their survey and the responses are given in Table 7 in terms of married or single.

Table 7

Personal characteristics of participants in terms of marital status

\begin{tabular}{lccccc}
\hline \multirow{2}{*}{ Marital status } & \multicolumn{2}{c}{ Welfare receiver } & \multicolumn{2}{c}{ Regular people } & \\
\cline { 2 - 6 } & Frequency & Percentage & Frequency & Percentage & Total \\
\hline Single & 35 & 70 & 18 & 38.3 & 53 \\
Married & 15 & 30 & 29 & 61.7 & 44 \\
Sum & 50 & 100 & 47 & 100 & 97 \\
\hline
\end{tabular}

The results of Table 7 show that there are more single people among welfare receivers than ordinary people. The results indicate that 70 percents of single people receive welfare while only 38.3 percents of ordinary people are welfare receiver. Table 8 summarizes the status of ordinary people and welfare receivers on entertainment. Based on the results, people who use welfare do not have much pleasure on their lives. The situation is not impressive for ordinary people since only 26 percents of people are satisfied with their entertainment.

Table 8

Personal characteristics of participants in terms of the entertainment

\begin{tabular}{lccccc}
\hline \multirow{2}{*}{$\begin{array}{l}\text { The quality of } \\
\text { leisure }\end{array}$} & \multicolumn{2}{c}{ Welfare receiver } & \multicolumn{2}{c}{ Regular people } & \\
\cline { 2 - 6 } & Frequency & Percentage & Frequency & Percentage & Total \\
\hline Very low & 16 & 32 & 5 & 10 & 21 \\
Low & 22 & 44 & 10 & 20 & 32 \\
Medium & 11 & 22 & 22 & 44 & 33 \\
High & 1 & 2 & 8 & 16 & 9 \\
Very high & 0 & 0 & 5 & 10 & 5 \\
Sum & 50 & 100 & 50 & 100 & 100 \\
\hline
\end{tabular}

\section{Statistical results}

In this section, we present some of statistical tests on the effects of different factors on quality of life based on t-student and Chi-Square.

\subsection{Nutrition}

Table 9 shows the results of the effects of Nutrition on the quality of life. 
Table 9

Statistical observation on the effects of Nutrition on quality of life

\begin{tabular}{lllllll}
\hline Status & Frequency & Average & Standard deviation & t-student & df & p-value \\
\hline Welfare receivers & 50 & 2.86 & 1.08 & \multirow{2}{*}{-2.97} & \multirow{2}{*}{98} & \multirow{2}{*}{0.004} \\
\hline Ordinary people & 50 & 3.48 & 0.99 & & \\
\hline
\end{tabular}

Based on the results we have in Table 9 the null hypothesis is rejected with $\alpha=0.01$, which means there is a meaningful difference between nutrition of welfare receivers and ordinary people.

\subsection{Healthcare}

Table 10 shows the results of the effects of healthcare on the quality of life.

Table 10

Statistical observation on the effects of healthcare on quality of life

\begin{tabular}{lllllll}
\hline Status & Frequency & Average & Standard deviation & t-student & df & p-value \\
\hline Welfare receivers & 50 & 2.22 & 1.01 & \multirow{2}{*}{-6.33} & \multirow{2}{*}{98} & 0.000 \\
\hline Ordinary people & 50 & 3.48 & 0.97 & &
\end{tabular}

Based on the results we have in Table 10 the null hypothesis is rejected with $\alpha=0.01$, which means there is a meaningful difference between healthcare of welfare receivers and ordinary people.

\subsection{Real state}

Table 11 shows the results of the effects of high quality real state on the quality of life.

Table 11

Statistical observation on the effects of real state on quality of life

\begin{tabular}{lllllll}
\hline Status & Frequency & Average & Standard deviation & t-student & df & p-value \\
\hline Welfare receivers & 50 & 2.58 & 1.05 & \multirow{2}{*}{-5.09} & \multirow{2}{*}{98} & \multirow{2}{*}{0.000} \\
\hline Ordinary people & 50 & 3.58 & 0.90 & & & \\
\hline
\end{tabular}

Based on the results we have in Table 11 the null hypothesis is rejected with $\alpha=0.01$, which means there is a meaningful difference between the quality of real state of welfare receivers and ordinary people.

\subsection{Employment}

Table 12 shows the results of the effects of employment and job on the quality of life.

\section{Table 12}

Statistical observation on the effects of employment on quality of life

\begin{tabular}{lllllll}
\hline Status & Frequency & Average & Standard deviation & t-student & df & p-value \\
\hline Welfare receivers & 50 & 2.53 & 0.95 & \multirow{2}{*}{-5.39} & \multirow{2}{*}{97} & 0.000 \\
\hline Ordinary people & 50 & 3.60 & 1.01 & & \\
\hline
\end{tabular}

Based on the results we have in Table 12 the null hypothesis is rejected with $\alpha=0.01$, which means there is a meaningful difference between the quality of jobs for the welfare receivers and ordinary people.

\subsection{Job opportunity}

Table 13 shows the results of the effects of job on the quality of life. 
Table 13

Statistical observation on the effects of high pay job on quality of life

\begin{tabular}{lllllll}
\hline Status & Frequency & Average & Standard deviation & t-student & df & p-value \\
\hline Welfare receivers & 50 & 1.78 & 0.93 & -7.33 & 98 & 0.000
\end{tabular}

Based on the results we have in Table 13 the null hypothesis is rejected with $\alpha=0.01$, which means there is a meaningful difference between job opportunities of welfare receivers and ordinary people.

\subsection{Social relationship}

Table 14 shows the results of the effects of social relationship on the quality of life.

Table 14

Statistical observation on the effects of social relationship on quality of life

\begin{tabular}{lllllll}
\hline Status & Frequency & Average & Standard deviation & t-student & df & p-value \\
\hline Welfare receivers & 50 & 3.38 & 1.10 & -2.23 & \multirow{2}{*}{98} & \multirow{2}{*}{0.028} \\
\hline Ordinary people & 50 & 3.82 & 0.84 & & \\
\hline
\end{tabular}

Based on the results we have in Table 14 the null hypothesis is rejected with $\alpha=0.05$, which means there is a meaningful difference between social relationship of welfare receivers and ordinary people.

\subsection{Marital status}

The other hypothesis is to see whether there is any meaningful relationship between the marital status of welfare receivers and ordinary people. We have performed Chi-Squre test to make this comparison. We get $\chi=9.82$, which is well above the critical value with $\chi_{1}^{0.05}=6.63$. Therefore, we could conclude that there is a meaningful relationship between marital status of welfare receivers and ordinary people.

\subsection{Entertainment}

Table 15 shows the results of the effects of entertainment on the quality of life.

Table 15

Statistical observation on the effects of entertainment on quality of life

\begin{tabular}{lllllll}
\hline Status & Frequency & Average & Standard deviation & t-student & df & p-value \\
\hline Welfare receivers & 50 & 1.94 & 0.79 & -5.35 & \multirow{2}{*}{98} & \multirow{2}{*}{0.000} \\
\hline Ordinary people & 50 & 2.96 & 1.08 & & \\
\hline
\end{tabular}

Based on the results we have in Table 15 the null hypothesis is rejected with $\alpha=0.01$, which means there is a meaningful difference between entrainment of welfare receivers and ordinary people.

\subsection{Entertainment}

Table 16 shows the results of the effects of entertainment on the quality of life.

Table 15

Statistical observation for quality of life

\begin{tabular}{lllllll}
\hline Status & Frequency & Average & Standard deviation & t-student & df & p-value \\
\hline Welfare receivers & 50 & 3.16 & 0.65 & -5.04 & \multirow{2}{*}{98} & \multirow{2}{*}{0.000} \\
\hline Ordinary people & 50 & 3.88 & 0.77 & & \\
\hline
\end{tabular}


Based on the results we have in Table 15 the null hypothesis is rejected with $\alpha=0.01$, which means there is a meaningful difference between the welfare receivers' lifestyle and ordinary people.

\section{Conclusion}

There are different welfare programs in various countries but the primary objective of all programs is to provide sufficient support for people who have difficulty managing their lives. The average monthly welfare payment in Iran is about $25 \$$, which is well below the line of poverty of approximately $600 \$$ and there are over four million people out of seventy five million population under this support. The purpose of this paper was to see whether there is any meaningful relationship between the quality of life of the welfare receivers and ordinary people and the results of our survey for two groups of fifty people indicated that there is definitely a meaningful difference between various components of quality of life between welfare receivers and ordinary people. The survey asked detailed questions on people's satisfaction on food, shelter, education, employment, entertainment, social relationship and marital status. Based on the statistical test performed, we could conclude that there is definitely a meaningful difference on all mentioned issues.

\section{References}

Aidukaite, J. (2009). Old welfare state theories and new welfare regimes in Eastern Europe: Challenges and implications. Communist and Post-Communist Studies, 42(1), 23-39.

Diwan, R. (2000). Relational wealth and the quality of life. Journal of Socio-Economics, 29(4), 305340.

Eamon, M.K., \& Kopels, S. (2004). 'For reasons of poverty': court challenges to child welfare practices and mandated programs. Children and Youth Services Review, 26(9), 821-836.

Fiva, J.H. (2009). Does welfare policy affect residential choices? An empirical investigation accounting for policy endogeneity. Journal of Public Economics, 93(3-4), 529-540.

Likert, R. (1932). A Technique for the Measurement of Attitudes. Archives of Psychology, 140, 1-55.

Massam, B.H. (2002). Quality of life: public planning and private living. Progress in Planning, 58(3), 141-227.

McKinnish, T. (2007). Welfare-induced migration at state borders: New evidence from micro-data. Journal of Public Economics, 91(3-4), 437-450.

Nannestad, P. (2007). Immigration and welfare states: A survey of 15 years of research. European Journal of Political Economy, 23(2), 512-532.

Onderstal, S. (2009). Bidding for the unemployed: An application of mechanism design to welfare-towork programs. European Economic Review, 53(6), 715-722.

Rose, N.E. (2001).Public employment programs, workfare, and welfare reform. Review of Radical Political Economics, 33(3), 281-286. 